\title{
THE THRESHER EDITORIAL PAGE
}
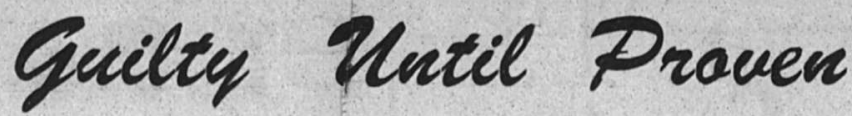

Innocent?

The administrative handling of the recent disturbance involving three Riee athletes warrants attention by all students. The action taken as a result of the incident shoild be enough to keep any Rice student out of trouble for a long time to come.

Upon learning of the altercation, a Rice spokesman said that the three "are suspended without prejudice pending a full investigation which will be made by the university." Such a statement implies that the normal judicial assumption has been inverted; these students are, in effect, judged guilty until proven innocent. "Suspension" is the word that is not easily erased from a student's record; it effects the decisions of professors, potential employers, and the jury which will judge the case. The trio has not been brought to trial in a court of law, but Rice has already judged them-"pending an investigation"!

The accounts in the Houston newspapers juxtaposed the Rice suspension with the details of the crime. The effect was that of disassociating those students from the university. Even though the administration did not wish its actions be construed in this way, it appeared as if the university decision was prompted by a desire to keep evil from blurring the Rice "image." In any event the Rice front office is guilty of either lacking foresight or of allowing principle to be sacrificed for the sake of public opinion.

The weekend situation is analogous in certain respects with that of the father who sees his son declared a juvenile delinquent and then deserts him in order to keep his own integrity. No matter what steps are taken to nullify the association, the trio are still "Rice boys" in the eyes of the community. If the father fails to stand by the son when the latter finds himself in trouble, it stands to reason that pop will find himself disowned when one of his sons achieves a noteworthy accomplishment.

Perhaps the administration would do well to remember that it once thought enough of these three students to admit them. 